Instructions for authors, subscriptions and further details:

Investigating Relationship among Research Self-Efficacy, Research Outcome Expectation, and Research Interest of Cambodian Faculty: Testing Social-Cognitive Theory

Phyrom Eam ${ }^{1}$

1) Hiroshima University, Japan

Date of publication: October $25^{\text {th }}, 2015$

Edition period: October 2015-February 2016

To cite this article: Eam, P. (2015). Investigating Relationship among Research Self-Efficacy, Research Outcome Expectation, and Research Interest of Cambodian Faculty: Testing Social-Cognitive Theory. International Journal of Sociology of Education, 4(3), 199-224. doi: 10.17583/rise.2015.1752

To link this article: http://dx.doi.org/10.17583/rise.2015.1752

PLEASE SCROLL DOWN FOR ARTICLE

The terms and conditions of use are related to the Open Journal System and to Creative Commons Attribution License (CC-BY) 
RISE - International Journal of Sociology of Education Vol. 4 No. 3 October 2015 pp. 199-224

\section{Investigating Relationship among Research Self- Efficacy, Research Outcome Expectation, and Research Interest of Cambodian Faculty: Testing Social-Cognitive Theory}

Phyrom Eam

Hiroshima University

(Received: 2 October 2015; Accepted: 6 October 2015; Published: 25 October 2015)

\section{Abstract}

This study set out to examine to what extent research self-efficacy and research outcome expectation predict research interest of Cambodian faculty. Participants in the study were 453 faculty members from ten major universities in the country. The main analyses were conducted using Hierarchical Multiple Linear Regression. The study detected that three blocks of independent variables (i.e. controlled personal and professional background variables, research self-efficacy, and research outcome expectation) explained about $37 \%$ of variances in research interest, with research self-efficacy accounting for the highest percentage of the total explained variances. Yet, the interaction effect of the research self-efficacy and research outcome expectation on research interest was not statistically significant. With terminal degree countries and disciplines as moderators, further moderation analyses indicated that the effect of research self-efficacy and research outcome expectation on research interest did not vary across disciplines and across places where participants obtained their terminal degree. Through these empirical analyses, this article offered some constructive thoughts on the current practices and policies of research culture building in the studied context.

Keywords: research in developing countries, academic profession, research culture and capacity 

October 2015 pp. 199-224

\section{La investigación de la relación entre la Autoeficacia, Expectativa de Resultados, e Interés de la Investigación de la Facultad de Camboya: Testando la Teoría Social - Cognitiva}

Phyrom Eam

Hiroshima University

(Recibido: 2 de Octubre 2015; Aceptado: 6 de Octubre 2015; Publicado: 25 Octubre 2015)

\section{Resumen}

Este estudio se propuso examinar en qué medida la autoeficacia y la expectativa de resultados de la investigación predicen el interés de ésta en la facultad de Camboya. Los participantes en el estudio fueron 453 profesores de las diez principales universidades del país. Los análisis principales se realizaron utilizando la regresión lineal múltiple jerárquica. El estudio detectó que tres bloques de variables independientes (variables de antecedentes personales y profesionales, es decir, controladas, la autoeficacia y la expectativa de resultados de investigación) explican alrededor del $37 \%$ de las variaciones en interés de la investigación, con la investigación de la contabilidad de la autoeficacia para el más alto porcentaje de la total varianza explicada. Sin embargo, el efecto de la interacción de la autoeficacia y la expectativa de resultados de investigación sobre el interés de la investigación no fue estadísticamente significativa. Con los países de grado de terminal y disciplinas como moderadores, una mayor moderación del análisis indicó que el efecto de la autoeficacia y la expectativa de resultados de investigación sobre el interés de la investigación no varió en todas las disciplinas y en los lugares donde los participantes obtuvieron su grado terminal. A través de estos análisis empíricos, este artículo ofrece algunas ideas constructivas sobre las prácticas actuales y las políticas de construcción de cultura de la investigación en el contexto estudiado.

Palabras clave: investigación en países desarrollados, profesión académica, cultura y capacidad de la investigación 


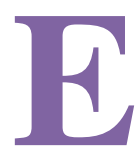

ducation, research, and services are the three key functions characterizing academic profession in our modern-day higher education system. It is increasingly difficult for policy makers and higher education workers and stakeholders to ignore the values and impacts of academic research or other genres of research conducted in higher education institutions (HEIs). Such extended significances of research give rise to studies on various constructs believed to have effects on research performance. Research interest is one of those key constructs believed to be linking with and explanatory of research performance (e.g. Kanh \& Scott, 1997; Bieschke, Herbert, \& Bard, 1998; Lent, Brown, \& Hackett, 1994). According to Kanh and Scott (1997), research interest was the key mediator that links personality types and research training environment to research productivity and career goals. Bishop and Bieschke (1998) correspondingly concluded: "Understanding the development of research interest is important precursor to building a testable, parsimonious model of research productivity."

However, discussions on faculty's research interest and factors affecting it have been limited and mostly conducted in the context of developed and semi-developed countries (e.g. Bishop \& Bieschke, 1998; Bard, Bieschke, Herbert, \& Eberz, 2000; Lambie \& Vaccaro, 2011). Those existing accounts fail to offer enough knowledge and thinking on this particular issue in the developing context of higher education. As a consequence, the development of research culture and performance has been sluggishly progressing in the developing world (Sanyal \& Varghese, 2006).

Research interest and factors explaining it are the central focus of this present study, and the discussed context of study is Cambodian higher education sector.

\section{Overview of Research in Cambodian Higher Education Sector}

Cambodian higher education seems to have been expanding rapidly in the past decades (Un \& Sok, 2014), reaching a point where its policy makers and stakeholders have started to rethink the path the nation's higher education is taking and to question the performance of their academics. Currently, the government has encouraged faculty to engage more actively in academic research at certain HEIs. Research policy has been put in place, 
small amount of research grants has been offered gradually, and more tangible promoting mechanisms of research culture have been considered and employed.

Despite such efforts, questions and doubts on what factors actually are key to promoting research interest of academics in this teaching-oriented, low-research-support academic environment have remained intact. Some previous studies (Kwok et al., 2010; Sam, Zain, \& Jamil, 2012; Chen, Sok, \& Sok, 2007; Tan \& Kuar, 2013) have raised a number of factors believed to explain the lack of engagement and interest in academic research activities of the country's university lecturers. Two seriously noted specific constructs among many found by those authors were the lack of research competence and low research motivation of the academic members. This argument has brought about the thinking that Cambodian academics will be more interested in research activities if they become research capable and are adequately incentivized. While widely raised and supported by other scholars and policy makers, these assumptions have yet to be tested empirically.

Thus, these three constructs - research interest, research self-efficacy (the proxy of research competence), and research outcome expectation (the proxy of research motivation) - are the principal theses of this particular study; specifically, the study seeks to test whether the belief in one's research selfefficacy and his/her expectation for benefits from engaging in research activities are the reasons that make Cambodian academics more or less interested in research activities. That being said, this study is less descriptive but more confirmatory and, in a sense, argumentative.

To synthesize, this sort of theoretically-based, explanatory investigation is the first in the studied context, making it potentially critical in informing policy as well as practices at the institutional level of higher education. The empirical testing approaches used in this study can be an assisting guide for policy thinking and decision making. Likewise, this present study is conducted to contribute to extending the body of literature on research culture building of developing and under-developed higher education systems which remains scarce till this day. 


\section{Theoretical and Empirical Backgrounds}

Different theoretical and conceptual models have been developed in the search for ways to improve engagement and performance in research activities or to understand characteristics and attitudes of successful researchers. A handful of scholars have paid attention on the study of interest, which generally refers to the patterns of likes, dislikes and indifference in certain activities (Hansen, 1984, as cited in Lent et al., 1994). Hence, research interest, herein, refers to the patterns of likes, dislikes and indifference in research activities. This construct has been acknowledged as a critical function that determines the endurable attitude to engage in research activities or to be research productive.

To explain the characteristics associated with research interest, SocialCognitive Theory (STC) (Bieschke et al., 1998; Lent et al., 1994; Phillip \& Russel, 1994) is perhaps one of the most used theoretical models. So far, SCT has been at the heart of our understanding of many social behaviors. The STC model uses the triadic reciprocal causation framework (i.e. behavior, external environment, and cognitive and other personal factors) to understand the psychosocial functioning of social behavior (Wood \& Bandura, 1989). Bard et al. (2000) conceived SCT as a "useful framework for examining research interest". Their study accordingly inclined them to consider variables in STC as critical elements in "the formation and persistence of research behaviors". In 1994, a further development and extension of this well-known model was introduced by Lent and his coresearchers, proposing that individual interest is important in reflecting the interaction between self-efficacy and outcome expectation over time. This latter-updated theory simply argued that faculty who believe that they have ability and skills to accomplish research activities effectively (i.e. having research self-efficacy) and those who anticipate worthy (either intrinsic or extrinsic) rewards from engaging in those research works (i.e. having research outcome expectation) are more likely to hold persistent interest in research activities (Lent et al., 1994). This present study draws on the basic concept of this model to test its hypotheses (proven in those past studies to have valid implications in boosting research interest in pragmatic contexts).

Empirical evidence from previous STC-based studies revealed that the two variables (i.e. research self-efficacy and research outcome expectation) 


\section{Eam-Research Interest}

have most of the time functioned as important and statistically significant predictors of research interest (Bishop \& Bieschke, 1998; Bard et al., 2000; Kanh \& Scott, 1998; Bieschke et al., 1998). Bard and other co-researchers (2000) claimed that research outcome expectation plays key roles in explaining the research interest of not only faculty but also graduate doctoral students of rehabilitation counseling programs. Their study showed from moderate to high positive correlation between research outcome expectation and research interest of the faculty. As for research self-efficacy, Gelso, Mallinckrodt, and Judge (1996), Lambie and Vaccaro (2011), and Rezaei and Zamani-Miandashti (2013) all similarly found a statistical significant association it [research self-efficacy] has with research interest. Another study, using Path Analysis to observe direct and indirect relationship among various research-related variables, of Kanh and Scott (1997) also detected that research self-efficacy is significantly, positively, and directly related to research interest. These two variables were also found to be directly or indirectly related to research productivity in other studies (e.g. Bieschke et al., 1998; Ramsden, 1999; Tien, 2007).

While the two variables have generally been the central thesis for investigation, other related variables have also been chosen for analyses to study their impacts on research interest. Some noticeable ones have been research training environment, personal characteristics (e.g. Holland's personality types), and professional characteristics of the participants. Studies, such as Galassi, Books, Stoltz, and Trexler (1986) and Gelso et al. (1996), argued that research training environment has influences on both research interest and research productivity.

Nevertheless, some debatable issues have emerged in those previous studies. One of the discussions has centered on whether it is research selfefficacy or research outcome expectation that poses more influences on research interest. While some of those studies found research outcome expectation and research self-efficacy to be of equivalent effects (Lent et al., 1994), other studies revealed that research outcome expectation is more predictive of research interest (Bard et al., 2000). Another gap to note in the literature is that most of the previous studies have been conducted in the field of psychology. Little attention has been paid to investigate impacts on research interest across different disciplines. Such discussions and gaps, while previously done and seen in the developed context (Bishop \& 
Bieschke, 1998; Lent et al., 1994), should be a practically worthwhile lesson for the developing context where the higher education system is generally characterized by limited monetary support available to invest in research development process and where policy makers really have to opt for a few most effective choices for implementation.

Obviously, while the theoretical concept is quite simple, the various studies in the literature seem to detect somehow complicated (and contradictory) patterns of the effects of key variables: that is, research outcome expectation and research self-efficacy on research interest. With these gaps remained unwell discussed, the present study aims to test the effects of a similar set of SCT variables on research interest of faculty in a different, least studied Cambodian higher education context. Likewise, the study also intends to investigate how the effects vary across disciplines and terminal degree countries.

\section{Research Questions and Hypotheses}

The main purpose of this study is to predict factors that influence research interest of Cambodian academics. Two main questions guide the whole research study: 1). How do research self-efficacy, research outcome expectation, and the interaction between the research self-efficacy and research outcome expectation affect research interest of Cambodian academics? and 2). Are the effects of those predictor variables on research interest vary across disciplines and terminal degree countries?

These research questions generated several hypotheses to be tested in the study. First, the study argued that personal and professional variables (i.e. gender, age, terminal degree and research experience) are directly correlated with research interest. However, these variables were used in later analyses just as controlled variables. Second, it was hypothesized that research selfefficacy has a direct, positive influence on research interest. Third, research outcome expectation has a direct, positive influence on research interest. Fourth, the moderation effect of the interaction between research selfefficacy and research outcome expectation significantly affects research interest. Fifth, different terminal degree countries where respondents graduated moderate the effect of research self-efficacy and research outcome expectation on research interest. Finally, different disciplines moderate the 
effect of research self-efficacy and research outcome expectation on research interest.

\section{Methodologies}

Similar to the majority of previous studies on factors affecting research interest, this study employed quantitative approach, with correlational research method and cross-sectional study design to investigate the patterns of the hypothesized relationships.

\section{Research Participants and Their Institutions}

The initial sample used in the analysis consisted of 453 university lecturers, herein referred to as faculty. Both terms (lecturers and faculty) were used interchangeably throughout the text. They are from ten different Cambodian major higher education institutions. One of the ten is officially called "institute", yet in practice its academic scope and capacity are of equivalent status with other major universities in the country. Of the ten, seven are public and three are private universities. Only two of them are located in provinces; the rest in the capital city, Phnom Penh, where most Cambodian universities are situated. There are seven comprehensive institutions providing academic services in various disciplines of study and three specialized institutions offering programs in only a few number of specific, related disciplines and/or fields. Reportedly from previous studies, five of the ten universities in the sample are research-engaged institutions.

\section{Sampling and Data Collection}

In order to obtain a similar concentration between respondents who have research experiences and those who do not, the study selected the ten universities on the purposive basis. All faculty working and teaching at the ten universities were the target samples. To reach them, a number of steps had to be achieved. First, the researcher sought permission from two authorities: Cambodian MoEYS which governs almost all of the selected universities and the management of each university. After permissions from the two were obtained, the researcher approached key personnel of each 
university who was assigned by the university management to facilitate the researcher's data collection. The main research instrument was a set of survey questionnaire. (The Variables section below indicated in details the key variables included in the questionnaire and used in the analysis.) Through those key personnel and their assistants, the researcher distributed the questionnaire in hard copies to all approachable faculty in each university. See Table 1 right below for the detailed characteristics of participants.

\section{Table 1}

Characteristics of participants in the study

\begin{tabular}{|c|c|c|c|c|}
\hline Variables (Code in SPSS) & Levels/Items (Measurement) & $f(\%)$ & $\overline{\boldsymbol{x}}$ & SD \\
\hline \multirow{2}{*}{ Gender (GENDER) } & $1=$ Male & $358(79)$ & 1.21 & .408 \\
\hline & $2=$ Female & $95(21)$ & & \\
\hline \multirow[t]{5}{*}{ Discipline (DISCIP3) } & $1=$ Social Science and related & $188(41.5)$ & 1.81 & .778 \\
\hline & fields & $163(36)$ & & \\
\hline & $2=$ Natural science and related & $102(22.5)$ & & \\
\hline & fields & & & \\
\hline & $3=$ Humanities and related fields & & & \\
\hline \multirow[t]{2}{*}{ Terminal degree (TERDEG2) } & $1=\mathrm{PhD}$ & $44(9.7)$ & 1.9 & .296 \\
\hline & $2=$ Lower than $\mathrm{PhD}$ & $409(90.3)$ & & \\
\hline Terminal degree country & $1=$ Graduated in Cambodia & $234(51.7)$ & 1.48 & .5 \\
\hline (TERDEGC) & $\begin{array}{l}2=\text { Graduated from a foreign } \\
\text { country }\end{array}$ & $219(48.3)$ & & \\
\hline Research experience & $0=$ No experience & $225(49.7)$ & .5 & .501 \\
\hline (RESEXP) & $1=$ Having experience & $228(50.3)$ & & \\
\hline Age (AGE) & Raw score & N/A & 34.98 & 8.361 \\
\hline Research self-efficacy (RSE) & 12 items; 1-5 Likert scale & N/A & 42.81 & 8.798 \\
\hline $\begin{array}{l}\text { Research outcome expectation } \\
\text { (ROE) }\end{array}$ & 8 items; $1-5$ Likert scale & N/A & 29.53 & 5.749 \\
\hline Research interest (RI) & 11 items; $1-5$ Likert scale & N/A & 40.86 & 8.432 \\
\hline
\end{tabular}

Note: All scale variables meet the assumptions of normal distribution, except Age; $\mathrm{SD}=$ Standard Deviation; N/A = Not Available; $\mathrm{f}(\%)=$ Frequency $($ percentage $) ; \overline{\mathrm{x}}$ $=$ Mean. 


\section{Variables}

Personal and professional variables consisted of the following variables. Age was measured by raw score by asking participants to fill in their real age. Terminal degree contained four groups originally $(\mathrm{PhD}$, Master's, Bachelor and Others) and was then recoded into two groups $(1=\mathrm{PhD} ; 2=$ Lower than $\mathrm{PhD}$ ) since the researcher was interested in testing the effect of faculty holding doctoral degree. Terminal degree countries referred to where the respondents had obtained their highest degree $(1=$ Graduated in Cambodia, 2 = Graduated from a foreign country). Disciplines variable initially consisting of seven major disciplines was trichotomized: $1=$ Social science and related fields; 2 = Natural science and related fields; and $3=$ Humanities and related fields. Research experience inquired respondents if they used to have experience in research prior to working in their current working institutions ( $1=$ No experience; 2 = Having experience). Most had experience with research during their post-graduate training.

Research self-efficacy, in this study, referred to the faculty's research confidence or belief that they obtain research knowledge and skills or can effectively accomplish research and research related tasks. It functioned as an independent variable in the study. Research self-efficacy was adopted from the shortened Research Self-Efficacy Scale developed by Kanh and Scott in 1997. The researcher dropped one irrelevant item and rephrased some items in order to ensure that Cambodian faculty understand each item fully in their own context. Those 12 items were measured by 1-5 Likert scale, with $1=$ Not confident at all to $5=$ Very confident. Then, the composite score of all items were computed to form the score of research self-efficacy. Some exemplary items were "Publishing research articles in professional journal outlets" and "Using research and statistical software (e.g. SPSS, Stata, SAS, NVIVO, or MAXQDA)". High score reflected high research self-efficacy. The Cronbach's Alpha value of these items was .933 $(n=443)$.

Research outcome expectation was also an independent variable in this study. The research outcome expectation scale was developed in a way that it covered both extrinsic and intrinsic rewards which faculty can expect provided that they get engaged in research activities at their respective institution. The tool contained 8 items (five extrinsic rewards and three 
intrinsic rewards) adapted from Chen, Gupta, and Hoshower (2006) and was measured by $1-5$ Likert scale, with $1=$ Not important at all and $5=$ Very important). Some exemplary items were "Receive increased salary or income" and "Fulfill my self-satisfaction for contribution of knowledge into my specialized discipline". The Cronbach's Alpha value of these items was $.794(n=440)$.

Research interest was the focused dependent variable in the study. It referred to how much faculty feel they like or dislike doing certain research activities. To measure research interest, an instrument developed by Bishop and Bieschke (1994), as cited in Vaccaro (2009), was adopted and, like previous variables, adjusted. The shortened 11 items were measured by 1-5 Likert scale, with $1=$ Not interested at all to $5=$ Very interested. Some exemplary items were "Engaging in actual research activities (e.g. data collection, site visit, experimentation, or interview)" and "Supervising or leading research teams or research students". The Cronbach's Alpha value was .926 $(n=442)$.

\section{Data Analysis}

Different statistical methods were used to analyze the data, using the Statistical Package for the Social Sciences (SPSS), version 21. Each of the two research questions drew on Hierarchical Multiple Linear Regression analyses. The first research question employed the Hierarchical Multiple Linear Regression to estimate how much variance in research interest is explained by four blocks/models of predictor variables: Block 1: personal and professional variables, Block 2: Block $1+$ research self-efficacy, Block 3: Block $2+$ research outcome expectation, and Block 4: Block $3+$ one cross-product term between research self-efficacy and research outcome expectation. This moderation-by-interaction cross-product term was standardized before being computed in order to avoid multi-collinearity.

The second research question aims to investigate whether the effects of predicator variables on research interest vary across disciplines and terminal degree countries or not. This is technically called moderation effects of multi-level moderators (i.e. disciplines and terminal degree countries). To do that, two more Hierarchical Multiple Linear Regression analyses were run, this time with the data split by three groups of disciplines and then by two 


\section{Eam-Research Interest}

groups of terminal degree countries. Before running the second-stage regression analyses, to test if there are significant differences on the level of research interest, the study also used one-way ANOVA (for the three-group disciplines) and independent-sample t-test (for the two-group terminal degree countries) to analyze the data.

Homogeneity of residual variance, multi-collinearity, influential cases, and linearity of the relationship among key variables were the four assumptions tested before proceeding with the interpretation of the statistical analyses results. First, Durbin-Watson test was used to understand the assumption of independence of residuals/errors. The value of DurbinWatson test (1.924) suggested that the residuals of variables were independent of each other. Multi-collinearity was not a concern for the accuracy of the model since the value of Tolerance was less than 1 and the VIF was lower than 10 (Tolerance ranging from .812 to .981 and Variance Inflation Factor (VIF) ranging from 1.019 to 1.231) when all independent variables were inputted into the analysis in Model 4. Cook's Distance values (Minimum $=.000$, Maximum $=.081$, Mean $=.002)$ proved that there was no influential case (outliers) affecting the model fit. Finally, the statistically significant correlation coefficient values (r) (see Table 2 below) indicted that the key variables were linearly related, while further proving that there was no multi-collinearity issue among independent variables. (The highest correlation coefficient value was .599.)

\section{Findings}

The major findings of the current study explained four pieces of relationship. First, the study tested if there is a significant direct relationship between research self-efficacy and research interest. Second, the study tested if there is a significant direct relationship between research outcome expectation and research interest. Third, the study observed the moderation effects of interaction between research self-efficacy and research outcome expectation on research interest. Finally, the study observed if the effects of research self-efficacy on research interest and of research outcome expectation on research interest vary across disciplines and terminal degree countries. Prior to all these main analyses, the controlled personal and professional variables were also investigated. 


\section{Relationship between Research Self-Efficacy, Research Outcome Expectation and Research Interest of Cambodian Faculty}

Table 2 below showed the correlation among all variables (gender, terminal degree, terminal degree country, research experience, age, research selfefficacy, research outcome expectation, and research interest). It should be noted that age was the only one demographic variable not significantly correlated with research interest. Research self-efficacy had a positive and high correlation with research interest $(\mathrm{r}=.599, \mathrm{p}<.01)$. Research outcome expectation also had a positive, but weaker, correlation with research interest $(\mathrm{r}=.27, \mathrm{p}<.01)$. It should be noted as well that the two independent variables (research self-efficacy and research outcome expectation) also had significantly positive, low correlation with each other $(\mathrm{r}=.319, \mathrm{p}<.01)$. This statistical results promptly supported further regression analysis on how much the two investigated, main independent variables explain the variation in the dependent variable (research interest).

Table 2

Pearson's correlation statistics of key variables

\begin{tabular}{|c|c|c|c|c|c|c|c|c|}
\hline & Variable & 1 & 2 & 3 & 4 & 5 & 6 & 7 \\
\hline & Gender & & & & & & & \\
\hline 2. & Terminal degree & $.096 *$ & & & & & & \\
\hline 3. & Research Experience & -.052 & -.028 & & & & & \\
\hline 4. & Age & $-.142 * *$ & $-.171 * *$ & $.248 * *$ & & & & \\
\hline 5. & $\begin{array}{l}\text { Research Self- } \\
\text { Efficacy }\end{array}$ & $-.181 * *$ & $-.216^{* *}$ & $.150 * *$ & -.005 & & & \\
\hline 6. & $\begin{array}{l}\text { Research Outcome } \\
\text { Expectation }\end{array}$ & -.082 & -.085 & .010 & -.087 & $.319 * *$ & & \\
\hline 7. & Research Interest & $-.132 * *$ & $-.118 *$ & $.139 * *$ & -.014 & $.599 * *$ & $.270^{* *}$ & \\
\hline
\end{tabular}

Note: $*=\mathrm{p}$-value $<.05, * *=\mathrm{p}$-value $<.01, * * *=\mathrm{p}$-value $<.001$

Table 3 illustrated two important evidence to support the research analysis. The result of the coefficient of determination $\left(\mathrm{R}^{2}\right)$ of each block of 


\section{Eam-Research Interest}

variables showed that some personal and professional variables significantly, but very trivially, explained (only .053\%) the variation in research interest. Research self-efficacy was a strong predictor of research interest, alone explaining $31 \%$ of the variation. Surprisingly, research outcome expectation statistically explained only $.07 \%$ of variation in the dependent variable. The adding of the interaction effects between research self-efficacy and research outcome expectation offered an additional minor $\mathrm{R}^{2}$ change $(.03 \%)$ of variation in research interest. The total variance explained by the four blocks of independent variables together was $37.2 \%$ (Adjusted $\mathrm{R}^{2}=36.2 \%$ ) in research interest. Presumably, it was revealed that all of the four blocks of independent variables were statistically significant models to predict research interest with the model-fit statistic all having p-value higher than .001 .

Table 3

Model Fit and $R^{2}$ statistical results

$\mathbf{R}^{2}$ Statistic

Models
Model Fit Statistic

(ANOVA)

$\mathrm{P}-$
Value

\begin{tabular}{lccccc} 
Model 1 (Personal and Professional & .053 & .044 & .053 & $6.249 * * *$ & .000 \\
Variables) & & & & & \\
Model 2 (Model 1 + Research Self- & .362 & .355 & .310 & $50.822^{* * *}$ & .000 \\
$\begin{array}{l}\text { Efficacy) } \\
\text { Model 3 (Model 2 + Research }\end{array}$ & .369 & .361 & .007 & $43.547^{* * *}$ & .000 \\
$\begin{array}{l}\text { Outcome Expectation) } \\
\text { Model 4 (Model 3 + Interaction }\end{array}$ & .372 & .362 & .003 & $37.716^{* * *}$ & .000 \\
Effect) & & & & & \\
\hline
\end{tabular}

Note: $*=$ p-value $<.05, * *=$ p-value $<.01, * * *=p$-value $<.001$

Table 4 was the key result that showed how each specific independent variable predicted research interest. It was obvious that in Model 1 (block 1), three personal and professional variables (gender, terminal degree, and research experience) were significant but poor predictors of research interest. The slope coefficient depicted that these variables were significant at p-value less than .01. Male faculty, faculty holding Ph.D. degree, and faculty with 
some research experience were likely to have higher research interest than were their counterparts. In Model 2 (block 2), research self-efficacy was inputted into the analysis, controlling for the personal and professional variables. The statistic $\left(\beta=.56, \mathrm{t}\right.$-statistic $=14.73, \mathrm{p}<.001, \mathrm{R}^{2}$ Change $=$ .31 ) indicated that research self-efficacy was a strong, significant predictor of research interest. With the presence of research self-efficacy, the first model's significant variables turned to be insignificant, indicating that research self-efficacy had much more effect on research interest than those personal and professional variables did. Model 3 (block 3) controlling for Model 1 and Model 2 inputted research outcome expectation into the analysis. Research outcome expectation did significantly predict research interest $\left(\beta=.13\right.$, t-statistic $=2.22, \mathrm{p}<.001, \mathrm{R}^{2}$ Change $\left.=.007\right)$. Yet, the result seemed to indicate that research outcome expectation was not as strongly explanatory of research interest as was research self-efficacy. It should be noted that, upon entering research outcome expectation, research self-efficacy remained statistically significant $(\mathrm{p}<.001)$ and most of the personal and professional variables remained insignificant. The finally analyzed moderation effect by interaction between research self-efficacy and research outcome expectation on research interest in Model 4 (block 4) was not statistically significant, however. 


\section{Eam-Research Interest}

Table 4

Hierarchical multiple linear regression analysis results

\begin{tabular}{|c|c|c|c|c|c|c|c|c|}
\hline \multirow[t]{2}{*}{ Variables } & \multicolumn{2}{|c|}{ Model 1} & \multicolumn{2}{|c|}{ Model 2} & \multicolumn{2}{|c|}{ Model 3} & \multicolumn{2}{|c|}{ Model 4} \\
\hline & $\beta$ & $\mathbf{t}$ & $\beta$ & $\mathbf{t}$ & $\beta$ & $\mathbf{t}$ & $\bar{\beta}$ & $\mathbf{t}$ \\
\hline Constant & 52.21 & $15.015^{* * * *}$ & 17.53 & $4.73 * * *$ & 14.27 & $3.6 * * *$ & 14.81 & $3.72 * * *$ \\
\hline Gender & -2.61 & $-2.71 * *$ & -.58 & -.72 & -.51 & -.64 & -.51 & -.64 \\
\hline $\begin{array}{l}\text { Terminal } \\
\text { degree }\end{array}$ & -3.32 & $-2.5^{*}$ & .24 & .21 & .32 & .28 & .23 & .21 \\
\hline $\begin{array}{l}\text { Research } \\
\text { experience }\end{array}$ & 2.55 & $3.19 * *$ & .96 & 1.44 & .99 & 1.49 & 1.04 & 1.57 \\
\hline Age & -.09 & -1.85 & -.03 & -.69 & -.02 & -.48 & -.02 & -.45 \\
\hline $\begin{array}{l}\text { Research } \\
\text { self- } \\
\text { efficacy }\end{array}$ & & & .56 & $14.73 * * *$ & .54 & $13.48 * * *$ & .53 & $13.28 * * *$ \\
\hline $\begin{array}{l}\text { Research } \\
\text { outcome } \\
\text { expectation }\end{array}$ & & & & & .13 & $2.22 *$ & .13 & $2.19 *$ \\
\hline $\begin{array}{l}\text { Research } \\
\text { self- } \\
\text { efficacy* } \\
\text { Research } \\
\text { outcome } \\
\text { expectation }\end{array}$ & & & & & & & -.42 & -1.5 \\
\hline
\end{tabular}

\section{Moderation Effects of Different Disciplines and Graduating Countries}

Another task of this study was to detect how the effects of research selfefficacy and research outcome expectation on research interest of Cambodian academics vary across disciplines and terminal degree countries. Table 5 showed that the mean score of faculty from natural science and related fields, those from social science and related fields, and those from humanities and related fields did not very much. The F-statistic indicated 
that there was no statistical significant differences among disciplines in terms of research interest. However, there was a statistically significant difference between locally graduating faculty and those graduating from a foreign country with regards to the level of research interest (Mean $1=$ 39.56; Mean $2=42.26$; p-value <.001).

Table 5

Test of statistical difference on research interest

\begin{tabular}{|c|c|c|c|c|c|}
\hline Variable & Groups & Mean & $\mathbf{n}$ & F-test/t-test & $\begin{array}{l}\text { p- } \\
\text { value }\end{array}$ \\
\hline \multirow[t]{4}{*}{ Disciplines } & $\begin{array}{l}1=\text { Social Science and related } \\
\text { fields }\end{array}$ & 41.05 & 188 & .433 (F-test) & .649 \\
\hline & $2=$ Natural Science and related & 41.07 & 163 & & \\
\hline & fields & 40.18 & 102 & & \\
\hline & $3=$ Humanity and related fields & & & & \\
\hline \multicolumn{6}{|l|}{ Terminal } \\
\hline degree & $1=$ Gradated in Cambodia & 39.56 & 234 & $-3.45(\mathrm{t}$-test) & .001 \\
\hline countries & $\begin{array}{l}2=\text { Graduated from a Foreign } \\
\text { country }\end{array}$ & 42.26 & 219 & & \\
\hline
\end{tabular}

Note: 'n' $=$ number of sample; $*=$ p-value $<.05, * *=$-value $<.01, * * *=p$-value $<.001$

A further analysis to test if the effects of the predictor variables (gender, terminal degree, research experience, age, research self-efficacy, and research outcome expectation) vary across disciplines and terminal degree countries employed the same approach of Hierarchical Multiple Linear Regression. The results illustrated by Table 6 below indicated that there was seemingly no moderating effects of disciplines and terminal degree countries on the relationship between significant predictor variables and research interest. These data-split analyses showed that there were not enough evidence to accept the hypotheses that aimed to detect the effects of the moderators, disciplines and terminal degree countries, yet the analysis interestingly and additionally explained the patterns of effect sizes of the tested independent variables. To be more specific, some variables (i.e. research outcome expectation and gender) detected significant in Table 4 above turned to be no longer significant when the data was analyzed separately by disciplines. Likewise, research outcome expectation was no 


\section{Eam-Research Interest}

longer significant when the sample of locally graduating faculty was analyzed alone. This indicated that those variables such as gender and research outcome expectations were not strong predictors of research interest. Contradictorily, research self-efficacy remained statistically significant across disciplines and terminal degree countries, suggesting that it was a very strong and stable predictor of research interest.

Table 6

Regression results across disciplines and terminal degree countries

\begin{tabular}{|c|c|c|c|c|c|}
\hline Variables & $\begin{array}{l}\text { Social science } \\
\text { and related } \\
\text { fields } \\
(n=188)\end{array}$ & $\begin{array}{l}\text { Science and } \\
\text { related fields } \\
\quad(n=163)\end{array}$ & $\begin{array}{c}\text { Humanities } \\
\text { and related } \\
\text { fields } \\
(\mathrm{n}=102)\end{array}$ & $\begin{array}{l}\text { Graduating } \\
\text { in Cambodia } \\
(n=234)\end{array}$ & $\begin{array}{c}\text { Graduating } \\
\text { from a } \\
\text { foreign } \\
\text { country } \\
(\mathrm{n}=219)\end{array}$ \\
\hline Constant & $15.46^{*}$ & $13.2 *$ & 6.39 & $15.5^{*}$ & $13.13^{*}$ \\
\hline Gender & .04 & .03 & -1.72 & -.88 & -.35 \\
\hline Terminal degree & -.47 & 1.05 & 1.93 & -.34 & .95 \\
\hline $\begin{array}{l}\text { Research } \\
\text { experience }\end{array}$ & .69 & .19 & $2.84 *$ & 1.53 & .44 \\
\hline Age & -.02 & -.02 & .02 & -.07 & .04 \\
\hline $\begin{array}{l}\text { Research self- } \\
\text { efficacy }\end{array}$ & $.54 * * *$ & $.51 * * *$ & $.6 * * *$ & $.58 * * *$ & $.48 * * *$ \\
\hline $\begin{array}{l}\text { Research } \\
\text { outcome } \\
\text { expectation }\end{array}$ & .13 & .15 & .17 & .12 & $.17 *$ \\
\hline $\mathrm{R}^{2}$ & .327 & .367 & .478 & .392 & .331 \\
\hline Adjusted $\mathrm{R}^{2}$ & .305 & .343 & .445 & .376 & .312 \\
\hline F (Sig) & $14.65 * * *$ & $15.08 * * *$ & $14.48 * * *$ & $24.37 * * *$ & $17.5^{* * * *}$ \\
\hline
\end{tabular}

Note: $*=\mathrm{p}$-value $<.05, * *=\mathrm{p}$-value $<.01, * * *=\mathrm{p}$-value $<.001$ 


\section{Discussions and Limitations}

This study explored the relationship among key three variables of SocialCognitive Theory: research self-efficacy, research outcome expectation and research interest, aiming to offer insights from empirical evidence into the current attempts of Cambodian higher education institutions and the policy level to come up with focused mechanisms to make research culture function. The following discussion centered on the direct effects of the two significant predictor variables (and some controlled demographic variables) on research interest of Cambodian academics, and further offered explanation on the insignificant effects of interaction and moderation variables.

The controlled personal and professional variables were found significant when entered into the analysis by just themselves, but with very low predicting ability $\left(R^{2}=.053\right)$. This suggested that male faculty $(\beta=-2.61)$, faculty with Ph.D. degree $(\beta=-3.32)$, and those with higher researcher experience $(\beta=2.55)$ are more interested in research activities. This result seemed to agree with some previous studies in the literature. Interesting enough, when new blocks of variables (research self-efficacy and research outcome expectation) were inputted into the analysis, personal and professional variables were no longer significant. It indicated that personal and professional variables do not likely pose much or very significant influences on research interest in Cambodian context, and that they can be somehow influenced by other variables.

Inputting research self-efficacy into the analysis posed a very significant, positive influence on the variance of research interest $\left(\mathrm{R}^{2}=.362 ; \beta=.56\right)$. It indicated that research self-efficacy was the best predictor of research interest in the study as there was a significant increase in the value of explained variance in the level of research interest from $\mathrm{R}^{2}=.053$ to $\mathrm{R}^{2}=$ .362. Higher research self-efficacy means higher research interest. This finding confirmed the argument of Social-Cognitive Theory (Lent et al., 1994) arguing that the belief in one's ability to complete research tasks is related to his/her research interest. Previous studies such as that of Lambie and Vaccaro in 2011 also detected the same significant result - that is, higher research interest is associated with higher research self-efficacy with a similar effect size value. In Cambodian context, this finding implied 


\section{Eam-Research Interest}

that research capable faculty are more likely to accumulate higher curiosity in research affairs and probably find it less stressful in research than those who have low research capacity. So, they are more likely to engage in research activities since they know how to start and how to deal with challenges faced by overloaded research tasks.

Research outcome expectation was entered in the next stage of analysis. This variable also was observed to be a significant, positive correlate of research interest in this study, yet, surprisingly, the value of $\mathrm{R}^{2}$ change was very low (from .362 to .369). This indicated that research outcome expectation, while significant, is not strongly associated with research interest. Bieschke et al. (1998) found a similar trend that research outcome expectation were predictors of research interest. In actuality, finding a significant relationship between these two variables is very acceptable in most situations, reasons being that faculty who can expect appropriate economic returns or intrinsic rewards see more opportunities from research engagement and so are more interested in doing research.

What was surprising about the finding was the fact that research selfefficacy in this study had a much stronger effect size on research interest, compared to the research outcome expectation. This result contradicted with previous studies such as Lent et al. (1994) which found both of them to be of equivalent effect sizes and Bard et al. (2000) finding research outcome expectation to be a much better predictor (explaining $47 \%$ of variances compared to only $7 \%$ of variance explained research self-efficacy). This contradictory results may be due to the different research culture between the developed context of those previous studies (with more research-active and research capable faculty) and the developing context of this present study (with humble research culture and fewer number of research capable faculty). Obviously, in the studied context of Cambodia, such mechanisms to promote research interest of academics are not systematic and functional. Even though there are some existing research motivation practices in certain HEIs, faculty generally do not find the benefits satisfactory and worth their efforts.

Another noteworthy finding was the insignificant results of the interaction effect between research self-efficacy and research outcome expectation on research interest. In previous studies, research self-efficacy and research outcome expectation were found to be a significant mediator 
between vocational personality and research training environment in predicting research interest (Bard et al., 2000; Bishop \& Bieschke, 1986). However, in the current study, the tested interaction effect between research self-efficacy and research outcome expectation was not found statistically significant. This result can be explained again by the very low (or nonexistent) condition of research motivation in the Cambodian context - the low motivation that makes even some research-capable faculty to stay away from research career.

While criticizing scholars might question the results of this study due to the multi-disciplinary aspect, the current author conducted a further vital analysis to see if the effect of self-efficacy and outcome expectation on research interest vary among social science and related fields, humanities and related fields, and natural science and related fields. The results suggested that there was no statistical significance variation among distinctive disciplines. However, research outcome expectation was no longer significant when different disciplines were analyzed separately, suggesting that it was a weak predictor of research interest. It can be implied into the Cambodian context that the faculty, regardless of what fields they are in, seem to be just moderately interested in engaging themselves into research. Presumably, the question pertains more to how much they are capable of doing research or how much they think research will give them back something important. This suggested no effect (i.e. indirect effect) of disciplines on the relationship between research outcome expectation and research self-efficacy on research interest. It is possible that the overall low engagement in research activities in the focused context is the result of the very low or even nil research supports in almost all disciplines. The scant research funding from various unsustainable sources may go a bit to this discipline or that discipline. So, faculty engage in research when funding is there and do not do research when there is no funding. The country has yet to have a clear vision of what specific areas to invest in research and development.

Overall, the model in this study accounted for approximately $37 \%$ of the explained variance of research interest, with research self-efficacy the most influential predictor. It added a new supporting evident that, at the individual level, research self-efficacy in the STC is one of the key factors that leads to strong interest in research. Research self-efficacy, therefore, merits great 
attention from relevant bodies working to promote research culture in the country. One question might illuminate why research self-efficacy sheds more contributing influences on research interest than does research outcome expectation: that is, if the faculty do not possess skills and knowledge to conduct research and have low self-belief that they can overcome challenging research activities, will they want to or be able to engage in research if they are given a certain amount of extrinsic incentives (such as bonuses or promotion)? It is likely not possible. From this corner of perspective, this scenario seems to indicate that research self-efficacy should come first as the main determinant of research interest.

Limitations: The study has two caveats. First the shortened scales were adjusted to fit Cambodian contexts and the comprehension of research and scholarship of faculty in this setting for the sake of validity. Doubtless, therefore, it may not be interpreted into the developed contexts of higher education where research outputs are more obvious. Second, the study did not handle two key variables in the literature: the personality types of faculty and the research training environment. Further studies should look at these two variables more critically.

\section{Implications}

It seems obvious that the results of the study, in some ways, inform both policy and practice of research development at Cambodian HEI setting. What the study concludes is that research self-efficacy or, in other words, the knowledge and skills and awareness and the ability to conduct research tasks are the most important variable that must be taken into great care by policy makers and higher education stakeholders. Wood and Bandura (1998) argued that self-efficacy belief is beyond acquiring skills and knowledge and it encompasses the resilient self-belief in ones' capabilities to handle difficult or different situations to achieve ones' goals. This low-self-efficacy philosophy, found in the developing context, should speak to factors leading to inactive research engagement of Cambodian faculty, and perhaps to other developing countries. As previously claimed, self-efficacy belief can affect the academics' psychological well-being and performance, their stress resilience, and their thought patterns; and these, in turn, can change their behavior to be more research active. 
Policy, therefore, should be designed in a way that HEIs offer opportunities for training and capacity building of research - from academic writing of research proposal, to conducting research, to managing research, and to publications and dissemination. For real practices at the institutional setting, the university management should also initiate training sessions right at their institutions to familiarize faculty with those earlier mentioned research activities. And to make the effort sustainable, university faculty recruitment and promotion should also consider the faculty experiences and ability to conduct research, while those faculty who already have research ability should be encouraged to mentor their colleagues. Mentorship is very important and practical for sustainable research culture (Delamont \& Atkinson, 2004, p. 49).

Let us pose some big questions to Cambodia: how many HEIs and programs can actually bear the authentic capacity to involve in research in their particular fields in the current setting? and how many Cambodian academics can actually do, teach and advance research capacity in their fields at a standard level of academic performance? The role of the government and HEIs is definitely to identify those capable people and bring them to the right place. The country really needs to have clear visions and direction for research and development: which field, which institution or program, and who, in order to ensure its future growth of research culture.

\section{Conclusion}

This study aims to detect the significant correlation between the two independent variables (research self-efficacy and research outcome expectation) and research interest of Cambodian academics, with the potential goal to understand the local reality of attitudes towards research in the studied setting which is just a starter in this scholarly world. The study shows that research self-efficacy is statistically significantly associated with research interest, explaining up to about $31 \%$ of variance in the dependent variable. Research outcome expectation, while also significantly related to research interest, does not radically explain the variation in the dependent variable.

Generally speaking, the literature and commonsense seem to assume that 


\section{Eam-Research Interest}

motivation or incentives are needed for Cambodian researchers to engage in research activities. The current researcher does not necessarily reject the idea but may argue in favor of the research competence, knowledge, and skills of academics to be the more important aspects to improve. This study used the case of the developing Cambodia with a very inactive research activities to reflect the author's argument. Through this finding, it can be concluded that it is worthwhile for the focused country, and perhaps other countries at the same level, to reconsider how to train and build capacity of the university lecturers and to give them authentic research experiences so that they can change their attitudes and level of interest towards research; otherwise, the dream for changes in research culture is not going to necessarily be translated into a meaningful and achievable ambition. To build research capacity, it is obviously not only the role of the government to set clear direction on which field to focus, which institution to do what, and how much funding to support. The higher education institutions themselves also have to truly change their policy and attitude towards research, have to truly value research, and have to make effective uses of capable resource persons and programs in their respective institutions.

\section{References}

Bard, C. C., Bieschke, K. J., Herbert, T. J., \& Eberz, A. B. (2000). Predicting research interest among rehabilitation counseling students and faculty. Rehabilitation Counselling Bulletin, 44(1), 48-55. doi: 10.1177/003435520004400107

Bieschke, J. K., Herbert, T, J., \& Bard, C. (1998). Using a social cognitive model to explain research productivity among rehabilitation counselor education faculty. Rehabilitation Education, 12(1), 1-6.

Bishop, M. R., \& Bieschke, J. K. (1998). Applying social cognitive theory to interest in research among counseling psychology doctoral students: A path analysis. Journal of Counseling Psychology, 45(2), 182-188.

Chen, Y., Gupta, A., \& Hoshower, L. (2006). Factors that motivate business faculty to conduct research: An expectancy theory analysis. Journal 
of Education for Business, 179-189. doi: 10.3200/JOEB.81.4.179189

Chen, C., Sok, P., \& Sok, K. (2007). Benchmarking potential factors leading to education quality: A study of Cambodian higher education. Quality Assurance in Education, 15(2), 128-148. doi: 10.1108/09684880710748901

Delamont, S. \& Atkinson, P. (2004). Successful Research Careers. Berkshire: Open University Press.

Galassi, P. J., Brooks, L., Stoltz, F. R., \& Trexler, A. K. (1986). Research training environments and student productivity: An exploratory study. The Counseling Psychologist, 14(1), 31-36.

Gelso, C. J., Mallinckrodt, B., \& Judge, A. B. (1996). Research training environment, attitudes towards research, and research self-efficacy: The revised Research Training Environment Scale. The Counseling Psychologist, 24, 304-322.

Kanh, J. H., \& Scott, N. A. (1997). Predictors of research productivity and science-related career goals among counseling psychology graduate students. The Counseling Psychologist, 25, 38-67.

Kwok, K. W., Chan, S., Heng, C., Kim, S., Neth, B., \& Thon, V. (2010). Scoping study: Research capacities of Cambodia's universities. Phnom Penh: CDRI.

Lambie, W. G., \& Vaccaro, N. (2011). Doctoral counselor education students' levels of research self-efficacy, perceptions of the research training environment, and interest in research. Counselor Education \& Supervision, 50, 234-258. doi: 10.1002/j.15566978.2011.tb00122.x

Lent, W. R., Brown, D. S. \& Hackett, G. (1994). Towards a unifying social cognitive theory of career and academic interest, choice, and performance. Journal of Vocational Behavior, 45. 79-122.

Phillips, J. C., \& Russell, R. K. (1994). Research self-efficacy, the research training environment, and research productivity among graduate students in counseling psychology. The Counseling Psychologist, 22(4), 628-641.

Ramsden, P. (1999). Predicting institutional research performance from published indicators: A test of a classification of Australian university types. Higher Education, 37(4), 341-358. 
Rezaei, M., \& Zamani-Miandashti, N. (2013). The relationship between research self-efficacy, research anxiety and attitude towards research: A study of agricultural graduate students. Journal of Educational and Instructional Studies in the World, 3(4), 69-78.

Sam, R., Zain, A. N., \& Jamil, H. (2012). Cambodia's higher education development in historical perspectives (1863-2012). International Journal of Learning \& Development, 2(2), 224-241. doi: 10.5296/ijld.v2i2.1670

Sanyal, B. C., \& Varghese, N. V. (2006). Research capacity of the higher education sector in developing countries. International Institute for Educational Planning, 1-12.

Tan, C., \& Kaur, S. (2012). Partnering and alliances in higher education [Monograph]. Higher Education Research Monograph, 17, 103-134.

Tien, F. F. (2007). Faculty research behavior and career incentives: The case of Taiwan. International Journal of Educational Development, 27, 4-17.

Un, L., \& Sok, S. (2014). Higher education governance in Cambodia. Leadership and Governance in Higher Education, 4, 72-94.

Vaccaro, N. (2009). The Relationship between Research Self-Efficacy, Perceptions of the Research Training Environment and Interest in Research in Counselor Education Doctoral Students: An Ex-PostFacto, Cross-Sectional Correlational Investigation (Doctoral dissertation). $\quad$ Retrieved from http://etd.fcla.edu/CF/CFE0002511/Vaccaro_Nicole_200905_PhD.p df

Wood, R., \& Bandura, A. (1989). Social cognitive theory of organizational management. Academy of Management Review, 14(3), 361-384.

Phyrom Eam is Graduate Student at Hiroshima University

Contact Address: Direct correspondence to Phyrom Eam at Graduate School for International Development and Cooperation, Hiroshima University, 1-5-1 Kagamiyama, Higashi-Hiroshima, 739-8529 Japan. E-mail: eamphyrom@yahoo.com 